\title{
Evolution of oxidation in soybean oil and its biodiesel under the conditions of the oxidation stability test
}

\author{
By G.G. Pereira ${ }^{a}$, S. Marmesat ${ }^{b}$, D. Barrera-Arellano ${ }^{a}$ and M.C. Dobarganes ${ }^{b, 凶}$ \\ ${ }^{a}$ Fats and Oils Laboratory, Faculty of Food Engineering, University of Campinas (UNICAMP), \\ CEP: 13081-970. Campinas, S.P., Brazil \\ ${ }^{\mathrm{b}}$ Instituto de la Grasa (CSIC). Avda. Padre García Tejero, 4. 41012 Sevilla, Spain \\ Corresponding author: cdobar@cica.es
}

\section{RESUMEN}

Evolución de la oxidación en el aceite de soja y su biodiesel en las condiciones del test de estabilidad a la oxidación

El objetivo de este estudio fue conocer la evolución de la oxidación del aceite de soja y de su biodiesel a $110^{\circ} \mathrm{C}$ en las condiciones del método estándar para la determinación de la estabilidad oxidativa, usando el aparato Rancimat. Las muestras se analizaron en diferentes períodos de tiempo hasta que el período de inducción fue sobrepasado. Se determinaron los índices de peróxidos y anisidina, los tocoferoles y los compuestos polares cuyos cambios están relacionados con el desarrollo de la alteración oxidativa. Además, fueron determinados el índice de acidez, la viscosidad y el contenido en ésteres, de interés en el análisis de la calidad del biodiesel. Los resultados indicaron que sólo el índice de peróxidos y el grupo de compuestos polares que incluye los hidroperóxidos (triglicéridos oxidados monómeros en el aceite y ésteres metílicos oxidados monómeros en el biodiesel) aumentaron durante todo el periodo de inducción. El final del período de inducción fue determinado por el marcado aumento de los compuestos de polimerización y la pérdida total de los tocoferoles. Sólo se observaron cambios significativos en el índice de acidez, viscosidad y contenido de ésteres al final del periodo de inducción.

PALABRAS CLAVE: Aceite de soja - Biodiesel - Compuestos polares - Índice de acidez - Índice de anisidina Índice de peróxidos - Oxidación - Tocoferoles - Viscosidad.

\section{SUMMARY}

Evolution of oxidation in soybean oil and its biodiesel under the conditions of the oxidation stability test

The objective of this study was to know the evolution of the oxidation of soybean oil and biodiesel under the conditions of the oxidation stability test $\left(110^{\circ} \mathrm{C}\right)$ using the Rancimat apparatus. Samples were analyzed at different periods of time until the end of the induction period. The analytical determinations related to the changes in oxidation include peroxide value, anisidine value, natural tocopherols and polar compounds. Acid value, kinematic viscosity, polymers and ester content were also analyzed because of their relevance in the evaluation of biodiesel quality. Results showed that only peroxide value and the group of polar compounds including hydroperoxides, i.e. oxidized monomeric TAG in the oil and oxidized monomeric FAME in the biodiesel increased significantly during the early oxidation stage. The end of the induction period was marked by a rapid increase in polymerization compounds and the exhaustion of tocopherols. Significant changes in acid value, viscosity and ester content were only observed after the end of the induction period.

KEY-WORDS: Acid value - Anisidine value - Biodiesel - Oxidation - Peroxide value - Polar compounds - Soybean oil - Tocopherols - Viscosity.

\section{INTRODUCTION}

Lipid oxidation takes place through a set of autocatalytic reactions that produce a high number of new compounds. Hydroperoxides, the primary oxidation compounds, decompose and give rise to a variety of secondary oxidation products. The oxidation of oil is influenced by numerous variables, i.e. the fatty acid composition, processing, temperature, minor compounds with prooxidant or antioxidant activity, etc., so that it is difficult to foresee the evolution of oxidative deterioration (Choe and Min, 2006). At the same time, the evaluation of the oxidation status in oils is complex and requires the application of more than one analytical method for a better understanding of the level of both primary and secondary oxidation compounds present in a certain sample (Frankel, 2005).

Biodiesel is an alternative fuel derived from fats and oils obtained by a transesterification reaction with an alcohol, usually methanol and etanol (Pighinelli et al., 2011; Rashidet et al., 2012). The chemical nature of biodiesel makes it more susceptible to autoxidation during storage than conventional fuel (Siddharth and Sharma, 2011; Pullen and Saeed, 2012). Since biodiesel has the same fatty acid composition as its parent oil or fat with considerable amounts of unsaturated fatty acids, the evolution and evaluation of oxidation in biodiesel present similar problems to those mentioned above for oils.

Oxidative degradation during storage decreases the oil and biodiesel quality (Dunn, 2002; Lacoste and Lagardere 2003) although no standard analytical methods have been proposed to evaluate 
the oxidation status of biodiesel. Measuring the level of primary oxidation compounds by means of peroxide value is one of the important indexes established for the quality evaluation of fats and oils but it has not been considered for biodiesel quality and it would be of interest to know its evolution throughout the biodiesel induction period. For edible refined oils, the peroxide value must be lower than 10 meq $\mathrm{O}_{2} \mathrm{~kg}^{-1}$.

Oxidation stability is the only standard method for the quality evaluation of biodiesel which is indirectly related to oxidation as it measures the susceptibility to oxidation and not the oxidation level at a certain moment. An induction time of at least $6 \mathrm{~h}$ at $110^{\circ} \mathrm{C}$ has been established in Europe and higher than $3 \mathrm{~h}$ in the USA (Rashid et al., 2012) although there is no explanation for the more restrictive European regulation. Although the oxidation stability method using the Rancimat apparatus is based on the standard methods for fats and oils, a minimum limit for edible oil commercialization has not been established, probably due to the enormous differences in fat and oil compositions.

It has been claimed that acid value and viscosity are also useful for monitoring oxidation (Dunn, 2002; Knothe, 2007; Pullen and Saeed, 2012). On one hand, esters first oxidize to form peroxides which then undergo complex reactions, including a split into more reactive aldehydes which further oxidize into acids which increase the acid value. On the other hand, the formation of polymeric secondary oxidation products increases viscosity and can lead to the formation of gums and sediments that clog filters. Thus, viscosity would be a useful measure for monitoring oxidation progression. However, both phenomena occur at the end of the induction period at high peroxide values and after the exhaustion of antioxidants when oxidation becomes uncontrolled (Márquez Ruiz et al., 1996; Martín-Polvillo et al., 2004).

The objective of this paper was to study the comparative oxidation of soybean oil and its biodiesel. In a first approach, we evaluated oxidation until the end of the induction period under the conditions established in the standard analytical method for oxidation stability. The increase in primary and secondary oxidation products, i.e. peroxide value and anisidine value, respectively, as well as the loss in natural tocopherols have been monitored. In addition, polar compounds which give quantitative information on the new oxidation compounds formed have been analyzed. For comparative purposes, acid value, kinematic viscosity and ester content were also measured at the end of the induction period.

\section{MATERIALS AND METHODS}

\subsection{Samples}

Soybean oil was supplied by Koipe S.A. (Andújar, Jaén, Spain). Soybean biodiesel was obtained in the laboratory.

\subsection{Biodiesel preparation}

Fatty acid methyl esters (FAME) were obtained by mixing $100 \mathrm{~g}$ of soybean oil, $250 \mathrm{~mL}$ of hexane, and $35 \mathrm{~mL}$ of sodium methoxide 1.5 $\mathrm{N}$. This reaction was conducted under constant stirring at ambient temperature during 30 minutes. After the transesterification, the medium was acidified adding a solution of sulfuric acid in methanol $1 \mathrm{M}$. The reaction solution was washed twice with water to remove the glycerin and other impurities. The ester-hexane fraction was filtered with anhydrous sodium sulfate to eliminate traces of moisture and the hexane was removed under reduced pressure (Tomasevic and SilerMarinkovic, 2003).

\subsection{Oxidation treatment}

Lots of six samples of $10 \pm 0.1 \mathrm{~g}$ of either the oil or the biodiesel were placed into Rancimat tubes which were inserted into the heating block of the Rancimat device (Metrohm, Herisau, Switzerland), previously heated at $110^{\circ} \mathrm{C}$. In each experiment, the range of oxidation time was chosen to satisfactorily monitor the evolution of oxidation until the end of the induction period and was measured by the oxidation stability test. The air flow was 20 $\mathrm{L} \mathrm{h}^{-1}$ in all the experiments. The experiments were done in duplicate.

\subsection{Analytical techniques}

\subsubsection{Physico-chemical characterization}

Acid value, kinematic viscosity, ester content and oil stability at $110^{\circ} \mathrm{C}$ were determined by the European Standard (CEN, 2003a, 1999, 2003b, 2003c, respectively). Peroxide value and anisidine value were determined following the AOCS Methods $\mathrm{Cd} 8 \mathrm{~b}-90$ and $\mathrm{Cd}$ 18-90, respectively (AOCS, 1997).

\subsubsection{Fatty acid composition}

Fatty acid composition was determined according to the IUPAC Standard Method 2.302 (IUPAC, 1992). Soybean oil was first derivatized to fatty acid methyl esters (FAME) with $2 \mathrm{M} \mathrm{KOH}$ in methanol following IUPAC Standard Method 2.301 (IUPAC, 1992). An Agilent 6890 GC system (Palo Alto, United States) equipped with a split/ split-less injector, an Innowax capillary column (30 $\mathrm{m}$ length, $0.25 \mathrm{~mm}$ i.d., $0.20 \mu \mathrm{m}$ film thickness) and a flame ionization detector (FID) was used. Hydrogen was used as carrier gas. The detector and injector temperatures were $250^{\circ} \mathrm{C}$. The initial oven temperature was $180^{\circ} \mathrm{C}$ and a temperature gradient from 180 to $220^{\circ} \mathrm{C}$ at $3^{\circ} \mathrm{C} \mathrm{min}^{-1}$ was applied. The injections were performed using a split ratio of $1: 5$. 


\subsubsection{Determination of total and free glycerol, and mono-, di-, and triacylglycerols in soybean biodiesel}

The standard determination was applied to the biodiesel sample following the European Standard EN 14105 (CEN, 2003d). Separations were performed on a Hewlett-Packard 5890 series gas chromatograph with cold on-column injection on a TBR 5 CB Low bleed/MS fused silica capillary column, $15 \mathrm{~m} \times 0.25 \mathrm{~mm}, 0.1 \mu \mathrm{m}$ (Teknokroma, Barcelona, Spain) and with detection by a flame ionization detector. Hydrogen was used as carrier gas at a column head pressure of $70 \mathrm{kPa}$. The analyses were run using hydrogen as carrier gas at a pressure of $41.3 \mathrm{kPa}$ and with the following oven temperature program: $50^{\circ} \mathrm{C}$ rising at $15^{\circ} \mathrm{C} \min ^{-1}$ to $155^{\circ} \mathrm{C}$, held for $10 \mathrm{~min}$, and further heating at $7^{\circ} \mathrm{C} \mathrm{min}^{-1}$ to $210^{\circ} \mathrm{C}$, held for $7 \mathrm{~min}$ and a final heating to $340^{\circ} \mathrm{C}$, held for $15 \mathrm{~min}$. The flame ionization detector was set at $350^{\circ} \mathrm{C}$.

\subsubsection{Quantitation and distribution of total polar compounds in oils}

The content of total polar compounds was determined gravimetrically according to IUPAC Standard Method 2.507 (IUPAC, 1992) with slight modifications. Thus, the non-polar and polar fractions were separated from $1 \mathrm{~g}$ of oil by silica column chromatography. The non-polar fraction, which contains the triacylglycerols (TAG), was eluted with $150 \mathrm{~mL}$ of $\mathrm{n}$-hexane/diethyl ether $(90: 10, v / v)$. A second fraction, which comprises the total polar compounds, was eluted with $150 \mathrm{~mL}$ of diethyl ether. The solvents were evaporated and the contents of the nonpolar and polar fractions were determined gravimetrically. The efficiency of the separation was checked by thin layer chromatography using hexane/ diethyl ether/acetic acid $(80: 20: 1, \mathrm{v} / \mathrm{v} / \mathrm{v})$ for the development of plates and exposure to iodine vapor to reveal the spots. The polar fraction was analyzed by high-performance size-exclusion chromatography (HPSEC) to determine the content of oligomeric, dimeric and oxidized monomeric triacylglycerols (TAG), as well as diacylglycerols (DAG) and fatty acids (FA). A chromatograph equipped with a Rheodyne $7725 \mathrm{i}$ injector with a $10 \mu \mathrm{L}$ sample loop, a Knauer 1200 HPLC pump (Knauer, Berlin, Germany) and a Merck refractive index detector was used. The separation was performed on two 100 and 500 $\AA \mathrm{PL}$ gel columns $(30 \mathrm{~cm} \times 0.75 \mathrm{~cm}$ I.D.) packed with porous, highly cross-linked polystyrenedivinylbenzene copolymers (film thickness $5 \mu \mathrm{m}$ ) (Agilent Technologies, Santa Clara CA, United States) connected in series. Tetrahydrofuran $\left(1 \mathrm{~mL} \mathrm{~min}^{-1}\right)$ was used as the mobile phase and samples were analyzed at concentrations between 15 and $20 \mathrm{mg} \mathrm{mL}^{-1}$ in tetrahydrofuran (Dobarganes et al., 2000).

\subsubsection{Quantitation and distribution of total polar FAME in biodiesel}

Biodiesel was separated by silica column chromatography following the procedure described above for polar compounds with the exception of the solvent used to elute nonpolar FAME. Due to the lower polarity of FAME as compared to TAG, hexane/diethyl ether (95:5) was used to elute a nonpolar fraction including the nonpolar FAME, and diethyl ether to obtain the polar fraction including unreacted TAG, partial glycerides and FA as well as oligomeric, dimeric and oxidized monomeric FAME (Dobarganes et al., 1984). Analysis of the polar fraction was performed by HPSEC, using the chromatographic conditions described above for polar compounds in oils. The methodology was described in detail, including calibration and reproducibility data, in earlier publications (Márquez-Ruiz et al., 1990).

\subsubsection{Determination of polymers}

Polymerized TAG and FAME were determined directly in the samples by HPSEC according to IUPAC Standard Method 2.508 (IUPAC, 1992).

\subsubsection{Determination of tocopherols}

Tocopherols were determined by HPLC with fluorescence detection (excitation at $290 \mathrm{~nm}$ and emission at $330 \mathrm{~nm}$ ), following the IUPAC Standard Method 2.432 (IUPAC, 1992). The column was a LiChrosorb Si $60(25064 \mathrm{~mm})$ packed with silica (5 mm particle size) (Merck, Darmstadt, Germany). Sample solutions of $50 \mathrm{mg} \mathrm{mL}$-1 were used and the mobile phase was $n$-hexane/isopropanol (99:1,

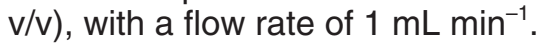

\section{RESULTS AND DISCUSSION}

Table 1 shows the physico-chemical characteristics of both soybean oil and biodiesel. The initial refined soybean oil had good quality as demonstrated by the low values of peroxide, acid and anisidine as well as the percentage of polar compounds. When comparing the oil and the biodiesel, small differences were found in the indexes but not in the main constituents, i.e. fatty acids, or in the tocopherol contents. Differences in polar compounds are expected because of the increase in nonpolar FAME through transesterification of partial glycerides present in the oil. However, the level of polar FAME was even higher than expected due to the presence of unreacted material, as shown in Table 2, and was quantified according to the standard method EN14105. The lower viscosities of FAME as compared to TAG also explain the differences found.

Differences in oxidation stability $(8.5 \mathrm{~h}$ for soybean oil versus $5.6 \mathrm{~h}$ for biodiesel) were 
Table 1

Physico-chemical characteristics of the initial soybean oil and biodiesel

\begin{tabular}{|c|c|c|c|}
\hline \multicolumn{2}{|c|}{ Analysis } & Oil & Biodiesel \\
\hline \multicolumn{2}{|c|}{ Acid value (mg KOH $100 \mathrm{~g}^{-1}$ ) } & 0.4 & 0.9 \\
\hline \multicolumn{2}{|c|}{ Peroxide value (meq $\mathrm{O}_{2} \mathrm{Kg}^{-1}$ ) } & 1.0 & 5.0 \\
\hline \multicolumn{2}{|l|}{ Anisidine value } & 3.1 & 0.4 \\
\hline \multicolumn{2}{|c|}{ Oxidation stability $\left(\mathrm{h}, 110^{\circ} \mathrm{C}\right)$} & 8.5 & 5.6 \\
\hline \multicolumn{2}{|c|}{ Viscosity $\left(\mathrm{mm}^{2} \mathrm{~s}^{-1}\right)$} & 31.0 & 4.2 \\
\hline \multicolumn{2}{|c|}{ Polar compounds/Polar FAME (\%) } & 4.8 & 2.8 \\
\hline \multicolumn{2}{|l|}{ Ester content $(\%)$} & - & 96.3 \\
\hline \multicolumn{2}{|c|}{ Tocopherols $\left(\mathrm{mg} \mathrm{kg}^{-1}\right)$} & 801 & 785 \\
\hline \multirow[t]{5}{*}{ Major fatty acids } & C 16:0 & 10.6 & 10.7 \\
\hline & C 18:0 & 3.3 & 3.3 \\
\hline & C $18: 1$ & 21.9 & 21.5 \\
\hline & C 18:2 & 51.3 & 51.2 \\
\hline & C $18: 3$ & 6.0 & 5.9 \\
\hline
\end{tabular}

Values are means of duplicate analyses

Table 2

Unreacted material in soybean biodiesel

\begin{tabular}{lc}
\hline \multicolumn{1}{c}{ Glycerides } & wt \% \\
\hline Free Glycerol & 0.02 \\
Total Glycerol & 0.10 \\
Monoacylglycerols & 0.22 \\
Diacylglycerols & 0.07 \\
Triacylglycerols & 0.16 \\
\hline
\end{tabular}

unexpected because of the slightly higher susceptibility against the oxidation of TAG as compared to FAME (Holman and Elmer, 1947). The level of tocopherols was similar in both systems but this does not justify the lower value found for biodiesel. Also, the presence of pro-oxidant metals in the biodiesel during its production was excluded by adding citric acid to chelate metals as there was no increase in the oxidation stability as compared to the initial sample. Therefore, the differences found could be due to the presence of other minor compounds found in higher contents in the biodiesel, such as free fatty acids, which have pro-oxidant activity (Miyashita and Takagi, 1986; Choe and Min, 2006).

Figures 1 shows the increase in peroxide and anisidine values -two analytical indices of wide application to evaluate primary and secondary oxidation products- as well as the parallel loss of total tocopherols in soybean oil and biodiesel, respectively. As can be observed, samples were obtained in both systems until the end of their induction periods (5.6 and $8.5 \mathrm{~h}$, respectively) were reached. The main difference between the oxidation of oil and biodiesel was the more rapid

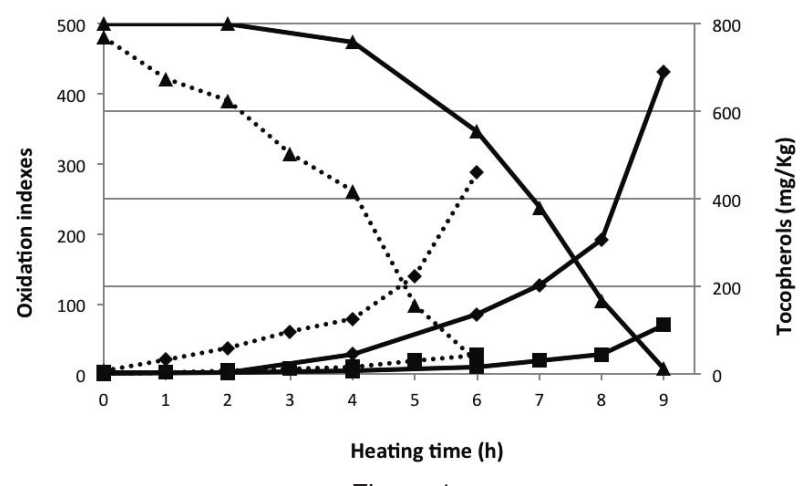

Figure 1.

Evolution of oxidation indexes in soybean oil (solid line) and biodiesel (dotted line) oxidized in Rancimat at $110^{\circ} \mathrm{C}$

$(\checkmark$ peroxide value, $\boldsymbol{\square}$ anisidine value and $\boldsymbol{\Delta}$ loss of tocopherols).

decay of tocopherols in the biodiesel. However, the profiles of oxidation were similar in both systems and characterized by an increase in peroxide value, related to the formation of primary oxidation compounds, throughout the oxidation period. However, the anisidine value related to the formation of secondary oxidation compounds changed moderately until the end of the induction period in parallel with the exhaustion of tocopherols. As found at room temperature (Martín-Polvillo et al., 2004), these results indicate that the formation of secondary oxidation products is low during the induction period even at $110^{\circ} \mathrm{C}$.

Table 3 summarizes the loss in individual tocopherols during the oxidation of both systems. Concerning the type of tocopherols, it is easily observed that $\alpha$-tocopherol was less stable than $\delta$-tocopherol, while $\beta$ - and $\gamma$-tocopherols degraded at intermediate rates. The relative stability of $\alpha-, \beta-, \gamma-$ and $\delta$-tocopherol has been previously reported either at low temperatures (Kamal-Eldin and Appleqvist, 1996; Lampi et al., 1999) or at high temperatures in food preparation like baking and frying (Yoshida et al., 1991; Lampi and Kamal Eldin, 1998; Barrera Arellano et al., 1999, 2002; Marmesat et al., 2008).

Table 4 shows the results for polar compounds in soybean oil. For each sampling point, total polar compounds and their distribution in oxidation compounds (oligomeric TAG, dimeric TAG and oxidized monomeric TAG) and hydrolytic products (DAG and fatty acids) were quantified. As can be observed, hydrolytic compounds did not change at the end of the induction period ( 8 and $9 \mathrm{~h}$ ), with the exception of fatty acids. Oxidized monomeric TAG, including mostly hydroperoxides, increased during the early stage of oxidation, while polymerization compounds did not increase until the stage of advanced oxidation.

Table 5 shows the results for polar FAME in soybean biodiesel. This determination allows for the direct evaluation of the total oxidized FAME formed and their distribution in oligomeric FAME, dimeric FAME and oxidized monomeric FAME. In the case of biodiesel, unreacted glycerides are also included in the polar FAME overlapping with polar FAME 
Table 3

Losses in $\alpha, \beta, \gamma$ and $\delta$ tocopherols content during the oxidation of soybean oil and biodiesel at $110^{\circ} \mathrm{C}$

\begin{tabular}{|c|c|c|c|c|c|c|}
\hline SAMPLE & Oxidation time (h) & $\alpha$ & $\beta$ & $\gamma$ & $\delta$ & Total \\
\hline \multirow[t]{7}{*}{ Soybean oil } & 0 & 123 & 31 & 469 & 178 & 801 \\
\hline & 2 & 121 & 29 & 473 & 180 & 803 \\
\hline & 4 & 86 & 17 & 466 & 177 & 746 \\
\hline & 6 & ND & 12 & 362 & 167 & 541 \\
\hline & 7 & ND & ND & 214 & 155 & 369 \\
\hline & 8 & ND & ND & 32 & 123 & 155 \\
\hline & 9 & ND & ND & ND & ND & ND \\
\hline \multirow[t]{7}{*}{ Soybean biodiesel } & 0 & 103 & 33 & 468 & 181 & 785 \\
\hline & 1 & 49 & 27 & 424 & 173 & 673 \\
\hline & 2 & 20 & 29 & 401 & 173 & 623 \\
\hline & 3 & $\operatorname{Tr}$ & 13 & 314 & 166 & 493 \\
\hline & 4 & ND & $\operatorname{tr}$ & 248 & 156 & 407 \\
\hline & 5 & ND & ND & 25 & 120 & 145 \\
\hline & 6 & ND & ND & ND & $\operatorname{tr}$ & $\operatorname{tr}$ \\
\hline
\end{tabular}

ND: not detected; tr: traces

Table 4

Evolution of polar compounds and their groups of components (\%) during the oxidationof soybean oil at $110^{\circ} \mathrm{C}$

\begin{tabular}{|c|c|c|c|c|c|c|}
\hline \multirow{2}{*}{$\begin{array}{l}\text { Oxidation Time } \\
{[\mathrm{h}]}\end{array}$} & \multirow{2}{*}{ Total } & \multicolumn{5}{|c|}{ Polar compound distribution } \\
\hline & & Polymeric TAG & Dimeric TAG & $\begin{array}{c}\text { Oxidized } \\
\text { monomeric TAG }\end{array}$ & DAG & Fatty acids \\
\hline 0 & 4.8 & ND & 0.5 & 2.6 & 1.3 & 0.5 \\
\hline 2 & 4.8 & ND & 0.4 & 2.7 & 1.3 & 0.5 \\
\hline 4 & 6.2 & ND & 0.5 & 3.8 & 1.4 & 0.5 \\
\hline 6 & 7.8 & ND & 0.6 & 5.3 & 1.3 & 0.6 \\
\hline 7 & 9.3 & ND & 1.1 & 6.6 & 1.3 & 0.4 \\
\hline 8 & 11.1 & ND & 1.6 & 7.8 & 1.1 & 0.6 \\
\hline 9 & 22.9 & 1.8 & 4.1 & 14.8 & 1.2 & 0.9 \\
\hline
\end{tabular}

TAG: triacylglycerols; DAG: diaylglycerols; ND: not detected

due to their similar molecular weight as indicated in Table 5. As expected, oxidized monomeric FAME was the only group of compounds quantified by HPSEC which increased during early oxidation, as did peroxide value, due to the fact that during the first stage of oxidation, oxidized monomeric molecules are largely hydroperoxides.

Table 6 summarizes the changes in the main indexes from the initial samples to the sampling points before and after the end of the induction period ( 8 and $9 \mathrm{~h}$ for soybean oil and 5 and $6 \mathrm{~h}$ for soybean biodiesel). As can be observed, acid value, viscosity, ester content and polymers had values close to the initial values just before the end of the induction period given by the oxidation stability test (5.6 and $8.5 \mathrm{~h}$ for the oil and biodiesel, respectively), while significant changes occurred once the induction period was overpassed. As reported by Lacoste and Lagardere (2002) at the end of the induction period measured by Rancimat, the samples tested did not fulfill the main specifications for biodiesel. Nevertheless, for the appropriate evaluation of changes in biodiesel quality, only those indexes which change significantly during the early stages of oxidation would be useful.

\section{CONCLUSIONS}

1. The profile of oxidation in both systems, at the usual temperatures applied in the oxidation 
Table 5

Evolution of polar FAME and their groups of components (\%) during the oxidation of soybean biodiesel at $110^{\circ} \mathrm{C}$

\begin{tabular}{ccccc}
\hline \multirow{2}{*}{$\begin{array}{c}\text { Oxidation time } \\
{[\mathrm{h}]}\end{array}$} & Total & \multicolumn{3}{c}{ Polar compound distribution } \\
\cline { 3 - 5 } & & Oligomeric FAME +TAG & Dimeric FAME + DAG & Oxidized monomeric FAME \\
\hline $\mathbf{0}$ & 2.8 & 0.3 & 0.4 & 2.1 \\
$\mathbf{1}$ & 3.2 & 0.3 & 0.4 & 2.5 \\
$\mathbf{2}$ & 3.4 & 0.3 & 0.5 & 2.6 \\
$\mathbf{3}$ & 3.5 & 0.3 & 0.5 & 2.7 \\
$\mathbf{4}$ & 3.8 & 0.3 & 0.5 & 3.0 \\
$\mathbf{5}$ & 4.5 & 0.3 & 0.7 & 3.5 \\
$\mathbf{6}$ & 10.9 & 0.8 & 1.4 & 8.7 \\
\hline
\end{tabular}

TAG: triacylglycerols; DAG: diacylglycerols

Table 6

Changes in the oxidation and quality indexes from the initial to the end of the induction period in soybean oil and biodiesel oxidized at $110^{\circ} \mathrm{C}$

\begin{tabular}{lccccccc}
\hline Sample & $\begin{array}{c}\text { Oxidation time } \\
(\mathbf{h})\end{array}$ & $\begin{array}{c}\text { Acid value } \\
\left(\mathbf{m g ~ K O H ~ g}^{-1}\right)\end{array}$ & $\begin{array}{c}\text { Viscosity } \\
\left(\mathbf{m m}^{2} \mathbf{~ s}^{-1}\right)\end{array}$ & $\begin{array}{c}\text { FAME } \\
(\%)\end{array}$ & $\begin{array}{c}\text { PV } \\
\left(\mathbf{m e q ~ O}_{\mathbf{~}} \mathbf{~ k g}^{-1}\right)\end{array}$ & $\begin{array}{c}\text { Anisidine } \\
\text { value }\end{array}$ & $\begin{array}{c}\text { Polymers } \\
(\%)\end{array}$ \\
\hline Oil & $\mathbf{0}$ & 0.40 & 31.0 & - & 1.0 & 3.1 & 0.4 \\
& $\mathbf{8}$ & 0.48 & 31.7 & - & 192 & 28.2 & 1.4 \\
& $\mathbf{9}$ & 1.9 & 36.5 & - & 431 & 70.8 & 5.7 \\
Biodiesel & $\mathbf{0}$ & 0.90 & 4.20 & 96.3 & 5.0 & 0.4 & 0.2 \\
& $\mathbf{5}$ & 0.96 & 4.25 & 94.3 & 140 & 20.0 & 0.4 \\
& $\mathbf{6}$ & 1.78 & 4.38 & 84.8 & 288 & 28.4 & 1.8 \\
\hline
\end{tabular}

stability test, was characterized by a gradual increase in peroxide value and oxidized monomeric compounds during the induction period, whose end can be determined by the exhaustion of the antioxidants and significant formation of polymerization compounds.

2. Significant changes in acid value or viscosity were observed only in the advanced stages of oxidation and consequently were not useful to measure the oxidation status during the induction period.

3. Peroxide value was the most useful index to measure the oxidation status of the oil and biodiesel during the induction period.

\section{ACKNOWLEDGEMENT}

We wish to thank the Brazilian Research Foundations: CAPES (Fellowship CAPES - Process $\mathrm{n}^{\circ}$ BEX 6667/12-0) and FAPESP.

\section{REFERENCES}

AOCS. 1997. Official methods and recommended practices of the American Oil Chemists' Society, 5th ed. AOCS, Champaign, IL.
Barrera-Arellano D, Ruiz-Méndez MV, Márquez-Ruiz G, Dobarganes MC. 1999. Loss of tocopherols and formation of degradation compounds in triacylglycerol model systems heated at high temperature. J. Sci. Food Agric. 79, $1923-1928$.

Barrera-Arellano D, Ruiz-Méndez MV, Velasco J, Márquez-Ruiz G, Dobarganes MC. 2002. Loss of tocopherols and formation of degradation compounds at frying temperatures in oils differing in unsaturation degree and natural antioxidant content. J. Sci. Food Agric. 82, 1696-1702.

CEN. 1999. EUROPEAN COMMITTEE FOR STANDARDIZATION. Method EN 3104. Liquid petroleum products - Determination of kinematic viscosity and calculation of dynamic viscosity. Brussels, Belgium, 1999.

CEN. 2003a. EUROPEAN COMMITTEE FOR STANDARDIZATION. Method EN 14104. Fatty acid methyl esters (FAME) - Determination of acid value. Brussels, Belgium.

CEN. 2003b. EUROPEAN COMMITTEE FOR STANDARDIZATION. Method EN 14103. Fatty acid methyl esters (FAME) - Determination of ester and linolenic acid methyl ester contents. Brussels, Belgium.

CEN. 2003c. EUROPEAN COMMITTEE FOR STANDARDIZATION. Method EN 14112. Fatty acid methyl esters (FAME) - Determination of oxidation stability. Brussels, Belgium, 2003 
CEN. 2003d. EUROPEAN COMMITTEE FOR STANDARDIZATION. Method EN14105. Fatty acid methyl esters (FAME) - Determination of free and total glycerol and mono-, di-, triglyceride contents. Brussels, Belgium, 2003.

Choe E , Min DB. 2006. Mechanisms and Factors for Edible Oil Oxidation. Rev. Food Sci. F. 5, 169-186.

Dobarganes MC, Pérez-Camino MC, Gutiérrez GonzálezQuijano R. 1984. Métodos analíticos de aplicación en grasas calentadas. I. Determinación de ésteres metílicos no alterados. Grasas Aceites 35, 172-177.

Dobarganes MC, Velasco J, Dieffenbacher A. 2000. The determination of polar compounds, polymerised triacylglycerols, oxidised triacylglycerols and diacylglycerols in fats and oils. Pure Appl. Chem. 72, 1563-1575.

Dunn RO. 2002. Effect of oxidation under accelerated conditions on fuel properties of methyl soyate (biodiesel). J. Am. Oil Chem. Soc. 79, 915-920.

Frankel EN. 2005. Methods to determine the extent of oxidation, in Frankel EN (Ed). Lipid Oxidation, 2nd ed, vol. 18. The Oily Press, Bridgwater, 99-127.

Holman RT, Elmer OC. 1947. The rates of oxidation of unsaturated fatty acids and esters. J. Am. Oil Chem. Soc. 24, 127-129.

IUPAC. 1992. Standard Methods for the Analysis of Oils, Fats and Derivatives, 7th ed. International Union of Pure and Applied Chemistry, Blackwell Scientific, Oxford, UK.

Kamal-Eldin A, Appleqvist LA. 1996. The chemistry and antioxidant properties of tocopherols and tocotrienols. Lipids 31, 671-699.

Knothe G. 2007. Some aspects of biodiesel oxidative stability. Fuel Process. Technol. 88, 669-677.

Lacoste F, Lagardere, L. 2003. Quality parameters evolution during biodiesel oxidation using Rancimat test. Eur. J. Lipid Sci. Technol. 105,149-155

Lampi AM, Kamal-Eldin A. 1998. Effect of $\alpha$ - and $\gamma$ tocopherols on thermal polymerization of purified high-oleic sunflower triacylglycerols. J. Am. Oil Chem. Soc. 75, 1699-1703.

Lampi AM, Kataja L, Kamal-Eldin A, Vieno P. 1999. Antioxidant activities of $\alpha$ - and $\gamma$-tocopherols in the oxidation of rapeseed oil triacylglycerols. J. Am. Oil Chem. Soc. 76, 749-755.
Marmesat S, Velasco L, Ruiz-Méndez MV, FernándezMartínez JM, Dobarganes MC. 2008. Thermostability of genetically modified sunflower oils differing in fatty acid and tocopherol compositions. Eur. J. Lipid Sci. Technol. 110, 776-782.

Márquez Ruiz G, Pérez-Camino MC, Dobarganes MC. 1990. Combination of adsorption and size-exclusion chromatography for the determination of fatty acid monomers, dimers and polymers. J. Chromatogr. 514, 37-44.

Márquez-Ruiz G, Martín-Polvillo M, Dobarganes MC. 1996. Quantitation of oxidized triglyceride monomers and dimers as an useful measurement for early and advanced stages of oxidation. Grasas Aceites 47, 4853.

Martín Polvillo M, Márquez-Ruiz G, Dobarganes MC. 2004. Oxidative stability of sunflower oils differing in unsaturation degree during long-term storage at room temperature. J. Am. Oil Chem. Soc. 81, 577-583.

Miyashita K, Takagi T. 1986. Study on the oxidative rate and prooxidant activity of free fatty acids. J. Am. Oil Chem. Soc.63, 1380-1384.

Pighinelli ALMT, Ferrari RA, Miguel AMRO, Park KJ. 2011. High oleic sunflower biodiesel: quality control and different purification methods. Grasas Aceites 62, 171-180

Pullen J, Saeed K. 2012. An overview of biodiesel oxidation stability. Renew. Sust Energy Rev. 16, 5924-5950.

Rashid U, Ibrahim M, Ali S, Adil M, Hina S, Bukhari LH, Yunus R. 2012. Comparative study of the methanolysis and ethanolysis of maize oil using alkaline catalysts. Grasas Aceites 63, 35-43.

Siddharth J, Sharma MP. 2011. Thermal stability of biodiesel and its blends: A review. Renew. Sust Energy Rev. 15, 438-448.

Tomasevic AV, Siler-Marinkovic SS. 2003. Methanolysis of used frying oil. Fuel Process. Technol. 81, 1-6.

Yoshida H, Hirooka N, Kajimoto G. 1991. Microwave heating effects on relative stabilities of tocopherols in oils. J. Am. Oil Chem. Soc. 56, 1042-1046. 